\title{
A DIMENSÃO EMPÍRICA DAS PROBABILIDADES: DETERMINISMO VS. INCERTEZA
}

\section{Manuel Menezes ${ }^{1}$}

\begin{abstract}
Resumo: Os intentos de controlo do contingente perdem-se na raiz dos tempos. Destarte, no presente ensaio, partindo do pressuposto de que a arte de enumerar e classificar consubstanciou uma via por intermédio da qual se visou implementar o controlo do corpo social, num primeiro momento, procurar-se-á mostrar como, a partir de finais da centúria de quinhentos, e com maior amplitude ao longo dos séculos seguintes, em Inglaterra (mas não só) as preocupações, tomando por base a experiência concreta, começaram a direcionar-se para a observação e o exame de alguns fenómenos populacionais, nomeadamente as taxas de nascimentos e óbitos, as taxas de reprodução e de fecundidade e os rácios entre sexos, entre outros. Num segundo momento, serão tomados também em consideração os discursos e as análises demográficas desenvolvidas no âmbito da Teologia Natural, com o intuito de mostrar como os mesmos procuram justificar a negação da importância da contingência recorrendo ao background religioso do seu pensamento.
\end{abstract}

Palavras-chave: Probabilidades, Aritmética Política, Teologia Natural, Determinismo, Contingência.

\begin{abstract}
The attempts to control chance are lost in the origin of time. So, in this paper, on the assumption that the art of enumerate and classify has crystallized a way through which was aimed to implement the control of the social body, in a first moment, we seek to show how, from the end of the five hundred century, and with greater amplitude over the next centuries, in England (but not only) the concerns, on the basis of concrete experience, began to focus in the observation and the examination of some population phenomena, in particular the rates of births and deaths, the rates of
\end{abstract}

\footnotetext{
${ }^{1}$ Doutor em Ciências da Comunicação (especialidade de Comunicação e Cultura) pela Faculdade de Ciências Sociais e Humanas da Universidade Nova de Lisboa. Docente no ISMT e na UCP - CRB.
} 
reproduction and fertility and the ratios between sexes, among others. In a second moment, the speeches and the demographic analyzes developed in the framework of Natural Theology will also be taken into account in order to show how they seek to justify the denial of the importance of chance by using the religious background of his thought.

Keywords: Probability, Political Arithmetic, Natural Theology, Determinism, Chance.

\section{NOTA INTRODUTÓRIA}

Os intentos conexos com o controlo do contingente, não tiveram como ponto de partida único as análises abstratas conexas com os Jogos de Azar. A perscrutação histórica dos discursos sobre a temática revela, de um modo clarividente, a existência de distintas formas de aproximação às probabilidades. Assim, o tomar em consideração da vertente empírica das probabilidades, do viés onde as preocupações recaíram sobre os fatos concretos da experiência, as regularidades mediadoras dos dados demográficos, justifica-se, desde logo, pelo fato de ter sido a partir desta perspetiva que viriam a ser desenvolvidas todo um conjunto de metodologias para a mensuração e o estudo dos fenómenos demográficos que, enquadrando o que viria a ficar conhecido sob a denominação de Aritmética Política, ulteriormente revelar-se-iam de extrema utilidade para a consubstanciação dos intuitos estatais de regulação e controlo do corpo social.

De igual importância se revela o aferir das possíveis influências exercidas pelo determinismo ao nível dos trabalhos levados a cabo no âmbito da Teologia Natural. Quer dizer, a questão a ser respondida é a de perceber como o determinismo teleológico associado à mesma se plasmou como marco organizador dos discursos desta matriz? Mais precisamente, procurar-se-á mostrar como a apreensão da contingência enquanto ausência de desígnio e o subsequente intuito de, simultaneamente, por um lado, negar à mesma qualquer papel regulador e, por outro, provar empiricamente (tomando por base a perfeição/harmonia evidenciados pela natureza) a existência da divina providência, se constituíram como propulsores essenciais do desenvolvimento dos trabalhos conexos com esta matriz.

\section{AS PROTOFORMAS DO ESTUDO NUMÉRICO DOS FENÓMENOS SOCIAIS}

«Arithmétique Politique, c'est celle dont les opérations ont pour but des recherches utiles à l'art de gouverner les 
peuples, telles que celles du nombre des hommes qui habitent un pays; de la quantité de nourriture qu'ils doivent consommer; du travail qu'ils peuvent faire; du temps qu'ils ont à vivre; de la fertilité des terres; de la fréquence des naufrages...»

(Denis Diderot, 1751).

O exemplo primo da matriz empírica das probabilidades emerge na Inglaterra. As preocupações dos estudiosos ingleses direcionaram-se, essencialmente, para os factos concretos da experiência. Em reforço do exposto, podemos aludir à asserção de Nightingale David, segundo a qual John Graunt «demonstrou, como nenhum outro do seu tempo, que a aproximação empírica dos ingleses à probabilidade, não se fez através da mesa de jogo, mas por intermédio da matéria-prima da experiência» (1962: 109).

Igualmente de nota, é o facto de esta vertente ter facilitado uma aproximação entre a teoria e a prática. Durante muito tempo a atitude (qualitativa) adotada pelos analistas dos seguros e das anuidades contrariou as regras gerais de avaliação (quantitativa) propostas pelos probabilistas para a determinação do risco. Segundo Lorraine Daston a avaliação do risco, colocando a ênfase no julgamento prudente e nas especificidades dos casos individuais, refletia um misto de experiência e intuição, não havendo, por exemplo, no caso do comércio marítimo regras muito definidas para a determinação dos preços dos seguros, excetuando a regra básica de quão «[...] maior era o risco (dependendo este da natureza da carga, da estação do ano, da rota adotada, da experiência do capitão, etc.), maior era o prémio, estimado com base numa percentagem do valor dos bens segurados» (1988: 119; 168-70).

Atendendo, então, ao exposto quanto ao hiato existente durante um longo período entre essas duas dimensões, seria na decorrência dos desenvolvimentos dos trabalhos realizados no âmbito desta perspetiva que os seguradores - que até aí calculavam os prémios sustentando-se, essencialmente, numa razoabilidade empírica - começaram a olhar com mais atenção para os tratamentos teóricos que vinham sendo desenvolvidos no tocante ao controlo da incerteza. No entanto, a aproximação referida seria algo morosa, emergindo os primeiros sinais da mesma somente a partir de meados do século XVIII, o que, em parte, talvez possa ser justificado devido, por um lado, à «[...] falta de unanimidade entre os matemáticos quanto à determinação da esperança de vida, à validade subjacente a certas suposições simplistas e à confiabilidade relativa de certas tabelas de vida» (Daston, 1988: 172). Por outro lado, tomando em atenção a provável a influência da esfera religiosa, não será descabido afirmar que a relutância em aceitar a teoria por parte dos seguradores se devia, em parte, ao facto de «[...] 
partilharem a crença vulgar de que um naufrágio ou uma morte acidental era mais uma questão conexa com a vontade divina do que com o cálculo» (Howie, 2002: 18).

Nesta matriz, vamos encontrar a preponderância de uma via utilitarista que, preocupada com as mortes decorrentes da peste, irá conduzir ao despoletar (a partir dos anos 30 do século XVI) de preocupações demográficas que se traduziriam no assomar de tábuas de mortalidade e dos registos paroquiais ${ }^{2}$ onde era feito o assentamento do número de batismos e de mortes por sexo e segundo a causa. Apesar de esporádicas num primeiro momento, viriam a assumir uma maior regularidade com o passar dos anos, verificando-se que, em 1625, já eram impressas listas semanais das 113 paróquias ${ }^{3}$ de Londres (David, 1962).

Dois dos nomes mais sonantes da Escola Inglesa, foram John Graunt (1620-1674) e William Petty (1623-1687), cujas exegeses, direcionandose para o estudo numérico dos fenómenos sociais, podem ser consideradas como o marco indiciador não só dos primórdios da dimensão pública das análises (Hacking, 1990), como também da interligação que, de um modo mais nítido, se começa a estabelecer entre a teoria das probabilidades e os conhecimentos estatísticos. No âmbito da «arte de bem governar», os trabalhos destes autores podem, de um modo geral, ser associados a «[...] a todo um conjunto de análises e de saberes que se desenvolveram depois do final do século XVI e tomaram toda a sua amplidão no século XVII, essencialmente esse conhecimento do Estado em seus diferentes dados, em suas diferentes dimensões, nos diferentes fatores de sua potência, e que se chamou, precisamente, de "estatística" como ciência do Estado» (Foucault, 1978: 295).

Sobre o primeiro, escreveu, em 1741, Johann Peter Süssmilch (17071767) - «de entre todos, Graunt é aquele que merece o maior elogio por ter desbravado o caminho conducente a essas novas verdades e pelo facto de as ter descoberto» (1741: 239). Este elogio viria a ser reforçado nas edições seguintes, onde Graunt é comparado a Cristóvão Colombo «mas, quem os utilizou [registos paroquiais], antes de Graunt, para descobrir aí uma ordem? A descoberta foi tão simples como a da América, mas faltava um Cristóvão Colombo que fosse mais além do que

\footnotetext{
2 Apesar das diretivas emanadas do Concílio de Trento (1545-63), onde se ordenava que todas as paróquias católicas deveriam manter registos de batizados e casamentos, esta não foi uma preocupação generalizada na Europa - «os governos diferiram grandemente na vivacidade e eficácia com que coligiram dados: a Suécia foi uma das primeiras, com a França logo a seguir, mas várias nações centrais da Europa não registaram nascimentos e mortes até ao século XIX» (Gigerenzer et al, 1989: 21; Daston, 1988: 127).

${ }^{3}$ De acordo com John Graunt (1662), as mesmas subdividiam-se em paróquias entremuros (97) e fora-de-muros (16).
} 
outros na análise das verdades e dos velhos dados conhecidos. Foi isto que ocorreu a Graunt, o primeiro a aperceber-se da existência de uma ordem nos registos de mortes e de doenças de Londres, levando-o à honrosa conclusão de que uma ordem similar poderia existir em outros domínios da vida humana» (1765: §15, 319).

A importância do seu trabalho no que pode ser considerado como a génese das investigações científicas sobre a população ${ }^{4}$ é, igualmente, reafirmada por autores contemporâneos, considerando-o como o fundador da «aritmética política» em Inglaterra (Hacking, 1990), o «inovador da teoria da amostragem» (Bernstein, 1996) ou, ainda, o co-fundador (com o segundo) da ciência da estatística moderna (David, 1962; Oberschall, 1987; Gigerenzer, 1989, 1996; Ferreira et al, 2002). Na ótica do próprio, a importância das suas observações - políticas e naturais -, é manifesta para a «arte de governar», na medida em que a sua execução, com vista à manutenção da $p a z$ e da abundância, torna-se mais adequada quando na posse dessas informações, i.e., «[...] o conhecimento claro de todas essas coisas, e de muitas mais, é necessário para uma boa, adequada e fácil administração e, mesmo para o equilíbrio entre as diferentes fações da Igreja e do Estado» (1662: 74). Noutros termos, apontando a segurança e o bem-estar da população como objetivos primos dessa arte, defende ser desaconselhável governar um Estado sem deter os conhecimentos necessários sobre a população. No fundo, pode-se afirmar que John Graunt, sem utilizar o termo aritmética política, realça a importância da mesma enquanto saber do Estado 5 .

As suas preocupações - distanciando-se das análises elementares da mortalidade conexa com a peste - direcionaram-se para o estudo das projeções demográficas. Partindo da análise dos registos de batismos e mortes ocorridos em Londres entre 1604 e $1661^{6}$, a inovação do seu

${ }^{4}$ Convém assinalar que o vocábulo população foi um neologismo cunhado pelo alemão George Obrecht em inícios do século XVII e a utilização do mesmo de uma forma generalizada só viria a ocorrer, por exemplo na França, no decorrer do século XVIII (Pasquino, 1991).

${ }^{5}$ Para o reforço do poder do Estado, foi imprescindível a fundação de um saber sobre si e sobre os Estados rivais ou, mais precisamente, a constituição de um saber político detalhado sobre o Estado, sobre a sua potência (e as possibilidades de a aumentar) e a dos outros Estados (mensuração dos diferentes tipos de potência). Para a consubstanciação do mesmo foi, então, necessário proceder a uma recolha exaustiva de informações conexas tanto com as dimensões positivas, como com os aspetos negativos que perpassavam o governo do Estado. Essa tarefa viria a ser confiada à aritmética política - utilizada com propósitos instrumentais visando facilitar o controlo da população.

6 Análises compiladas, naquele que pode ser considerado o primeiro tratado de aritmética política - «Natural and Political Observations Mentioned in a Following Index, and Made Upon the Bills of Mortality. With Reference to the Government, 
trabalho, encontra-se na sistematização que desenvolveu sobre os mesmos e, em última instância, nas ilações retiradas para o universo mais vasto de Inglaterra e/ou de outros países. Isto é, John Graunt definiu o que, posteriormente, viria a ficar conhecido como inferência estatística. Destas cabe destacar, para além das estimativas da população residente em Londres em 1661 - 384.000 (1662: 59-61) ${ }^{7}$, as análises conexas com a taxa de mortalidade, visto ter sido um dos primeiros autores a salientar que a morte (um dos fenómenos, à partida, mais incerto quando tomado na sua dimensão individual), para além das suas variações temporais obedecia a algumas regularidades. Mais especificamente, numa das primeiras tabelas de vida de que há conhecimento, viria a definir uma taxa de mortalidade constante, estimando que cerca de $3 / 8$ da população morreria em cada dez anos (1662: 61-62) ${ }^{8}$.

Em suma, podendo-se assinalar entre os seus maiores feitos o facto de ter descoberto as regularidades mediadoras de fenómenos aparentemente fortuitos/acidentais e, por conseguinte, uma ordem nos assuntos humanos, as suas análises pioneiras viriam a revelar «os conceitos teóricos básicos necessários à tomada de decisões sob condições de incerteza. Amostragens, médias e noções do que é normal compõem a estrutura do que iria, posteriormente, sustentar a ciência da análise estatística, colocando a informação ao serviço da tomada de decisões e influenciando nossos graus de crença sobre as probabilidades de eventos futuros» (Bernstein, 1996: 83).

Quanto a William Petty (um dos fundadores da Royal Society), sinopticamente podemos referir que, retomando as análises grauntianas, partindo dos padrões de mortalidade, natalidade, doença, entre outros, fez uma análise comparativa entre cidades inglesas e europeias, bem como em termos mais latos entre Inglaterra e outros países durante este período ${ }^{9}$. Utilizando preferencialmente o «número, peso e medida» em

Religion, Trade, Growth, Ayre, Diseases, and the Several Changes of the Said City» (1662).

${ }^{7}$ Para uma análise crítica do método utilizado e dos erros que o mesmo continha, cf. Hacking (1975).

${ }^{8}$ No respeitante a outras inferências grauntianas a partir das evidências apresentadas pelos dados relativos às amostras analisadas, sinopticamente podemos enunciar as: (i) estimativas de nascimentos por género, apontando uma maior regularidade de nascimentos do sexo masculino comparativamente ao feminino em Londres, com um ratio 14/13 (1662: 49); (ii) análises conexas com a esperança de vida à nascença $36 \%$ dos nados-vivos morreriam antes de atingir os 6 anos (1662: 15) e maior esperança de vida para os nados-vivos do sexo feminino. (cf., também, David, 1962; Hacking 1975; Daston, 1988; Bernstein, 1996).

9 Para uma enumeração sinóptica das temáticas trabalhadas neste âmbito por este autor, vide Diderot (1751: 678). 
vez de «palavras comparativas, superlativas ou argumentos intelectuais», por um lado, e, dado o seu desejo de pôr a estatística ao serviço do Estado, por outro, o seu trabalho adquire um interesse acrescido a partir do momento em que se constata que, estando consciente dos condicionalismos decorrentes da inexistência de dados estatísticos coligidos, foi um dos primeiros a propor a criação de um departamento governamental de estatística ${ }^{10}$. Este deveria analisar dados demográficos (conexos com os nascimentos, casamentos e mortes, bem como a distribuição por sexo, idade, nível de educação, entre outros), considerados de vital interesse para a consolidação do poder do Estado ${ }^{11}$, visto, permitirem a posse de conhecimentos conexos com a sua potência, poder, i.e., relativos aos indivíduos disponíveis para o serviço militar e para a arrecadação de impostos (Hacking, 1975; Bernstein, 1996).

Em última análise, as exegeses pettyanas podem ser consideradas como o marco iniciático da emergência da perceção da população enquanto problema económico e político, i.e., «a população-riqueza, a população-mão-de-obra ou capacidade de trabalho, a população em equilíbrio entre o seu crescimento próprio e os recursos de que dispõe» (Foucault, 1976: 29).

\section{TEOLOGIA NATURAL: A CONTINGENCIA ENQUANTO AUSÊNCIA DE DESÍGNIO}

«Neste contexto [teológico], acreditar na fortuna ou na boa e má sorte, era considerado, na melhor das hipóteses, um erro patético, e, na pior, uma personificação pagã das causas desconhecidas»

(Lorraine Daston, 1988).

A análise desta matriz adquire para nós uma substancial importância a partir do momento em que constatámos que, também, os seus discursos (especialmente os da centúria de setecentos) são atravessados pelo viés determinista. No entanto, a abordagem é feita em moldes distintos dos utilizados por outros teóricos das probabilidades. Nos primeiros o mesmo surge a priori, partindo a maioria dos autores do pressuposto da existência de um determinismo (quer fosse mecanicista ou teleológico)

10 De acordo com Ian Hacking, esta ideia também se encontrava presente em Gottfried Wilhelm Leibniz (considerado o «padrinho filosófico das estatísticas oficiais prussianas»), ideia essa, explícita numa premissa onde defendia que o «[...] padrão do poder de um Estado é a sua população, devendo o Estado possuir um departamento estatístico central para conhecer o seu poderio» (1990: 41).

${ }^{11}$ Nas palavras de Johann Peter Süssmilch, as suas análises «[...] iluminaram a útil influência que as mesmas exerceram sobre a política e a arte de governar» (1741: 292). 
que procuram justificar por intermédio das análises probabilísticas desenvolvidas. Nos segundos, surge à posteriori, porquanto, foi a constatação da existência de «regularidades» e de «padrões de normalidade» comprovados pelos primeiros estudos que, num primeiro momento, atraiu um conjunto de estudiosos para esta dimensão de análise, constatação essa que, posteriormente, viria a ser examinada e moldada de modo a ser justificada com base nesse mesmo determinismo teleológico.

$\mathrm{O}$ enunciado, não invalida que estejamos conscientes de o raciocínio já se encontrar à partida imbuído do determinismo teleológico, só que, ao nível da organização do discurso, ele surge à posteriori como justificação. Justificação essa, tão desejada que, por vezes, propiciava leituras enviesadas onde as regularidades eram empolgadas com o intuito de alcançar o objetivo ambicionado - «ao longo do século XVIII, matemáticos e aritméticos políticos [... possuíam] a convicção de que a demografia humana e, especialmente, a mortalidade eram regidas por simples regularidades. [...Tendendo as suas análises] a negligenciar os desvios nos dados a favor das regularidades esperadas que os atraíram para os dados em primeiro lugar» (Daston, 1988: 130; cf. Arisawa, 1957; Moxley, 1999).

Para além do referido, uma outra distinção pode ser assinalada, nomeadamente a conexa com as influências exercidas pela Teologia Natural neste tipo de análises. Antes de avançarmos devemos, então, plasmar um pouco o raciocínio que a perpassava. O mesmo, pode, sinopticamente, ser clarificado por intermédio do recurso a um dos seus representantes mais significativos, designadamente o irlandês Robert Boyle (1627-1691). Este autor, não convencido que a prova da existência divina poderia ser deduzida a partir de argumentos ontológicos, procurou prová-la empiricamente tomando por suporte o «desenho» da natureza.

$\mathrm{Na}$ sua aceção a existência de Deus deveria ser inferida a partir das manifestações da divindade na experiência, ou seja, através da constatação da perfeição (contrária à desordem que, em princípio, estaria adstrita à contingência) com que os organismos foram criados e da harmonia/equilíbrio existente entre os diferentes ecossistemas. Isto é, segundo este quadro argumentativo, todos os organismos e as complexas adaptações dos mesmos por nós observadas, teriam sido criados por um desígnio inteligente. A extrema importância atribuída a estas questões por Robert Boyle, expressa-se no legado deixado no seu testamento para se encontrarem provas da religião cristã que contrapusessem a argumentação dos ateus e dos infiéis. Legado esse, que iria impulsionar a realização de várias conferências sobre esta temática, designadamente as proferidas por William Derham (1657-1735) na Royal Society entre 1711 e 1712, onde o autor, mostrando-se menos interessado nas anomalias/desvios do que nas 
regularidades, procura demonstrar, com exemplos vários, como na criação do mundo é visível o projeto da Providência (Bonar, 1931; Hacking, 1990: 207; Daston, 1988: 132) ${ }^{12}$.

Deste modo, excetuando de um modo claro os exemplos de James Bernoulli e Abraham de Moivre, nas análises dos primeiros teóricos das probabilidades os traços da influência da Teologia Natural não são tão manifestos, começando os mesmos a emergir de um modo clarividente, somente, com as análises demográficas de John Arbuthnot (1667-1735), traços esses que, expressando a contínua refutação da contingência (associada à ausência de desígnio, de propósito) com base numa argumentação que apelava para evidências da ação e poder divinos na experiência $^{13}$, viriam a ser uma constante em todos os teólogos naturais até Darwin ${ }^{14}$ (Gigerenzer et al, 1989; cf. David, 1962: 103).

John Arbuthnot, viria a prosseguir os trabalhos desenvolvidos por John Graunt e William Petty. Num ensaio publicado na Philosophical Transactions of the Royal Society em $1710^{15}$, partindo do pressuposto da existência de um equilíbrio entre géneros, refuta a influência que, possivelmente, a contingência aqui poderia exercer e procura justificar o mesmo sustentando o seu argumento na existência da Divina Providência - «esta igualdade de homens e mulheres não é uma consequência da contingência, mas da Divina Providência trabalhando para um bom fim» (1710: 186$)^{16}$. Deste modo, o equilíbrio, num primeiro momento justificado com base na existência de Deus, acabava, em última instância, por se transformar na prova cabal da existência da Divina Providência.

Tomando, então, por base a análise dos batismos ocorridos em Londres ao longo de 82 anos (1629-1710), na sua aceção, se o ratio $(18 / 17)$ fosse regulamentado pela contingência, certamente se assistiria ao incremento de posteriores desequilíbrios entre os sexos, no entanto, isso

\footnotetext{
${ }^{12}$ Dentro do quadro dos denominados teólogos da Royal Society pode-se, igualmente, referir o bispo de Chester, John Wilkins (1614-1672) (Ian Hacking, 1975: 107).

${ }^{13}$ Segundo a aceção de Jean Bricmont (2001), os fautores deste discurso defendiam que o universo tinha sido feito em função de uma certa finalidade que, por sua vez, testemunhava - ela própria - a existência de Deus.

${ }^{14}$ Quanto a Charles Darwin, gostaríamos de assinalar que o mesmo, concebendo a contingência como um sinal da nossa ignorância quanto às causas que provocaram determinadas mudanças, não foi um fervoroso adepto da teoria das probabilidades. Neste sentido, a mesma não emergia de um modo assíduo nas suas análises e, quando se socorria dela, fazia-o «[...] sempre no sentido clássico, como uma propriedade do nosso conhecimento imperfeito e não como uma característica do funcionamento da natureza» (Gigerenzer et al, 1989: 66; cf. Moxley, 1999: 104).

15 Sob o título: «An Argument for Divine Providence, Taken from the Constant Regularity Observed in the Births of Both Sexes».

${ }^{16}$ Um argumento similar encontra-se, igualmente, presente em William Derham (cf. Bonar, 1931).
} 
não se verificava, porque, $\mathrm{o}$ «inteligente Criador», não negligenciando o perigo maior a que os homens estavam sujeitos e, por consequência, o maior número de mortes que era infligido a este sexo, «[...] fornece mais Homens do que Mulheres; e isso numa proporção aproximadamente constante $^{17}$. [... Seguindo este raciocínio conclui, então, que a] Poligamia é contrária à Lei da Natureza e à Justiça, e à Propagação da Raça Humana; pois onde os Homens e as Mulheres se encontram em igual número, se um Homem toma Vinte Mulheres, Dezanove Homens têm de viver em Celibato, o que é repugnante para o Desígnio da natureza; não é, igualmente, provável que Vinte Mulheres sejam tão bem fecundadas por um Homem como por Vinte» (Arbuthnot, 1710: 188-9) ${ }^{18}$. Clarificando, o ratio tinha um propósito, assegurar um número igual de homens e mulheres aquando da idade de casar e, assim sendo, nunca poderia ser adjudicado à contingência. Logo, constata-se que, nesta acepção, a contingência é entendida de acordo com o antigo sentido aristotélico, ou seja, como ausência de propósito, ordem ou causa (Gigerenzer et al, 1989: 276; cf. Arendt, 1978).

Um dos mais significativos discursos desta índole encontra-se, no contexto da Teologia Natural, nas exegeses encetadas pelo eclesiástico alemão Johann Peter Süssmilch. O mesmo, apesar das palavras elogiosas endereçadas aos trabalhos realizados por John Graunt e William Petty, só viria a tomar conhecimento das análises dos mesmos num momento posterior ao início das suas pesquisas (Süssmilch, 1741; cf. Arisawa,

\footnotetext{
${ }^{17}$ A demonstração matemática desta argumentação apresentada por John Arbuthnot viria a ser criticada por Nicholas Bernoulli (1687-1759). Segundo o autor, o ratio apresentado relativamente aos nascimentos por sexo, não permitia retirar a conclusão de que o mesmo não poderia ser produzido pela contingência, porquanto, em sua opinião se «lançarmos 14000 dados, cada um possuindo 35 faces, 18 brancas e 17 pretas, seria muito possível que o número de faces brancas e negras se aproximassem tanto ou mais umas das outras, do que o número de Rapazes e Raparigas nas Tábuas» (In Doctrine of Chances, 1756, apud Nightingale David, 1962: 265; cf. Isaac Todhunter, 1865: 130-131). O próprio Abraham de Moivre, apesar de se encontrar próximo do raciocínio de John Arbuthnot (chegando mesmo a defendê-lo nesta contenda, pois, em sua opinião, as considerações de Nicholas Bernoulli não eram relevantes para o cerne da argumentação de John Arbuthnot), tinha algumas dúvidas quanto à demonstração apresentada, defendendo que a via mais adequada, para a sustentação da existência da ordem e da sua origem divina, deveria ser a observação da experiência (Isaac Todhunter, 1865; Ian Hacking, 1975; Lorraine Daston, 1988).

${ }^{18}$ A argumentação contra a instituição poligâmica encontra-se presente em alguns dos discursos analisados, cf., entre outros, John Graunt (1662: 47-8); Johann Peter Süssmilch (1765: §251, §409, §434). Não obstante o referido, dever-se-á assinalar a existência, concomitante, de muitos autores deste período a proclamarem, com intuitos pró-natalistas, a defesa da poligamia ou dos casamentos temporários (Hermínio Martins, 2003).
} 
1957; Hecht, 1979). Conseguintemente, por um lado, afirma ter sido a obra de William Derham a sua primeira influência: «a primeira ideia para a presente obra, encontrei-a na Physico-Theology [1713 - MM] do eminente Derham, obra essa que, para além de pontos de vistas novos e numerosos, continha toda uma série de observações sobre os registos de nascimentos, mortes e casamentos que até aí tinham vindo a ser desenvolvidas pelos seus compatriotas. $\mathrm{O}$ facto dessas noções me serem desconhecidas, constituindo-se, portanto, como novas verdades, já era suficiente para despertar o meu desejo de prosseguir as pesquisas por essa via» (Süssmilch, 1741: 291). Por outro lado, referindo-se aos trabalhos dos autores ingleses, justifica o interesse e a novidade (na Alemanha) das suas próprias análises ${ }^{19} \mathrm{com}$ a necessidade de apresentar provas mais concludentes $^{20}$ da ação ou, se preferirem, aritmética divina - «o mérito maior desta obra [...], é o de produzir o reconhecimento da existência e da sagacidade da Divina Providência, que governa este mundo de acordo com desígnios benevolentes e sagazes» (1741: 292).

Seria este, então, o objetivo último que, em conjugação com uma dimensão moralizadora ${ }^{21}$, iria nortear explicitamente todo o seu tratado de demografia. O conjunto volumoso de dados aí analisados servem - para além da aritmética política subjacente aos mesmos -, para demonstrar que nada depende da contingência $(1765: \S 13,317 ; \S 16,320)$, na medida em que, se no imediato algo lhe atribuímos, isso deve-se somente à nossa ignorância ${ }^{22}$, à nossa incapacidade de compreender como a ordem se dissimula a si própria na experiência quotidiana $(1765: \S 409,500)$, pois: «[...] todas as ações, mesmo aquelas que, aparentemente, são realizadas

${ }^{19}$ As mesmas surgiram na esfera pública entre 1741 e 1765. Destas, cabe destacar «Die Götliche Ordnung in den Veränderungen des Menschlichen Geschlechts aus der Gerburt, dem Tode und der Fortpfläntzung Desselben Erwiesen», com uma primeira edição em 1741 e edições subsequentes em 1761-62 e 1765, edições essas que, devido às revisões profundas de que foram alvo (especialmente da 1 . $^{\mathrm{a}}$ para a $2^{\mathrm{a}}$ ), podem ser consideradas novos trabalhos (Arisawa, 1957).

${ }^{20}$ Esta convicção baseava-se no facto ter tido acesso a um volume mais significativo de dados, nomeadamente os registos prussianos, do que aqueles analisados pelos autores que o precederam (1765: 300).

${ }^{21}$ Esta dimensão é visível, por exemplo, na associação estabelecida entre a morte e o pecado, visto a maior taxa de mortalidade encontrada nas cidades ser atribuída, não às más condições sanitárias, mas, ao pecado (Hacking, 1990).

${ }^{22}$ A ignorância sendo, na aceção do autor, transitória, é um indicador de que, se assim o desejarmos, somos capazes de compreender o implícito - «se, na obscuridade onde nos encontramos, somos incapazes de nos darmos conta [da ordem], muito bem! Tanto melhor para nós, pois podemos ter a esperança de alcançar um dia a luz divina que, iluminando-nos, nos possibilitará compreender o conjunto das relações» (1765: $\S 17,322)$. 
livremente pelas pessoas racionais, são controladas e regidas por Ele» (1741: 292).

Todo o discurso é construído com o intuito de demonstrar um único facto: todo e qualquer fenómeno - por mais fortuito que pareça no imediato $-{ }^{23}$ é regulado mediatamente por uma ordem específica que o autor qualifica - «o presente estudo tem a propensão de demonstrar que, nos nascimentos, na multiplicação, na vida, na morte e nas causas da morte ${ }^{24}$, reina uma ordem constante, geral, perfeita e harmoniosa» (1765: $\S 12,317 ; \S 14,319$, sublinhado nosso ${ }^{25}$, comparável à mestria que perpassa a marcha de um regimento. Ordem essa que, na aceção do autor, encontra a sua primeira demonstração no discurso da revelação, i.e., tomando como ponto de partida o discurso presente no Génesis - «crescei e multiplicai-vos, enchei e dominai a terra» (Gn 1: 28 $)^{26}$, Johann Peter Süssmilch justifica que este preceito comprova o modo como, historicamente, a vontade divina foi ordenando as regras necessárias à consubstanciação do mesmo - (i) multiplicando o ser humano, (ii) calculando as causas de morte, (iii) dotando o seu corpo de uma natureza, estrutura e força, capazes de enfrentar qualquer situação adversa, (iv) ordenando sabiamente os recursos alimentares, (v) dotando o homem de razão e, por último, (vi) regulando a reprodução dos dois sexos (1765: §5$\S 10)$.

Quanto a esta última, o autor (no capítulo XXI do seu tratado) desenvolve a seguinte argumentação: a «ordem excelente na reprodução dos dois sexos» só pode ser regulada transcendentalmente. Assim sendo, a constância e equivalência que a perpassa nunca poderia ser uma consequência da contingência (1765: §421, 503-4), visto ser impossível à

\footnotetext{
${ }^{23}$ Adotando um raciocínio bernoulliano, defende que com aumento significativo dos dados perscrutados se dá uma aproximação evidente à ordem e, apesar de fazer referência a algumas situações dissemelhantes encontradas, afirma que essa aproximação acaba, em última instância, por minorar a sua importância (1765: §413, 502).

${ }^{24}$ No prefácio da primeira edição, menciona com mais detalhe este fenómeno: «num primeiro momento, podemos pensar que a morte marca indistintamente os homens em qualquer idade, mas, se observarmos melhor, percebemos que isso ocorre sempre segundo uma determinada proporção. E, como o próprio homem não existe para outro fim, acreditar, por conseguinte, na simples contingência é um absurdo risível; nós vemos, então, aqui a confirmação desta verdade: a atenção com que Deus olha para a espécie humana» (1741: 292).

${ }^{25}$ Sobre estas questões, cf. Daston (1988); Gigerenzer et al (1989).

${ }^{26}$ Segundo a acepção de Hermínio Martins «para os plenitudinários demoteológicos da época, a vocação da espécie humana, [seguindo a máxima bíblica], era ocupar todos os nichos ecológicos, todos os continentes, todos os lugares onde os homens possam viver, mesmo com grandes dificuldades, enfim, realizar a "colonização global do planeta"» $(2003: 40 ; 42)$.
} 
mesma produzir, por um lado, uma estabilidade no ratio dos nascimentos - «em todo lado e de um modo constante, em 20 ou 30000 nascimentos ocorridos num ano ou em vários anos, o número de rapazes é maior do que o de raparigas, sendo o ratio dos dois números de 21 para 20 ou de 26 para 25» (1765: §410, 501) e, por outro, uma estabilidade compensatória no ratio das mortes, porquanto, a mesma - «[...] é um pouco mais numerosa nos rapazes do que nas raparigas, parecendo suprimir os excessos na sua quase totalidade: entre os 15 e os 20 anos os dois sexos encontram-se em completa igualdade, tendo, cada um, a oportunidade de se casar» (1765: §14, 318; cf. §423, 505).

Será a este nível que Johann Peter Süssmilch se vai distanciar dos autores que o precederam, pois, em sua acepção, as justificações apresentadas por John Graunt, John Arbuthnot e William Derham (entre outros), para o facto de nascerem mais rapazes do que raparigas é invalidada pelos factos concretos, ou seja, não se pode justificar o excesso de rapazes com base no argumento de os mesmos ao longo da vida se encontrarem sujeitos a maiores perigos que lhe podem provocar a morte quando, logo desde a nascença e até à idade adulta, se verifica que a taxa de mortalidade no género masculino é superior à do género feminino (1765: §423-4, 505).

Enquanto tentativa de síntese do discurso süssmilchiano, pode-se, então, afirmar que a deteção de regularidades demográficas de longo curso, ao serem justificadas com base numa (i) causa - a existência de num projeto divino que visava o «crescimento» e a «multiplicação» da espécie humana, que produz um (ii) efeito - a perfeita conexão existente entre a reprodução dos dois sexos, evidenciam uma análise da experiência parametrada pela ação contínua de Deus nos negócios humanos, onde o papel adstrito à contingência é nulo.

\section{NOTA CONCLUSIVA}

À guisa de conclusão, gostaríamos de sinalizar que, podendo ser considerados os primeiros a intentar, a partir de análises demográficas, decifrar leis mediadoras da sociedade, os trabalhos levado a cabo pelos aritméticos políticos ingleses - John Graunt, William Petty -, constituindo-se como instrumentos facilitadores da administração territorial e do controlo das populações, vir-se-iam a revelar de extrema importância para a governação do Estado. Partindo da análise dos poucos dados de que dispunham (num primeiro momento, essencialmente, os disponibilizados pelos registos paroquiais), viriam a desbravar o caminho conducente ao posterior desenvolvimento da ciência estatística moderna. Neste sentido, realçámos o facto de as suas análises, direcionando-se para o estudo das projeções demográficas, terem propugnado, por um lado, a 
descoberta de regularidades várias e, por conseguinte, a ordem subjacente a fenómenos aparentemente acidentais e, por outro, a apreensão da população enquanto problema económico e político.

Tivemos, igualmente, oportunidade de salientar como, na esteira destes trabalhos pioneiros, autores de distintas nacionalidades passaram a direcionar, igualmente, os seus interesses para o estudo dos fenómenos demográficos. Sofrendo as influências da Teologia Natural, como marca indelével deste tipo de análises destacámos os intentos de os «padrões de normalidade» evidenciados pelos dados serem recorrentemente explicados tomando por base o argumento do desígnio. Dito de outro modo, mostrámos como o intenso desejo de explicitar empiricamente a prova da existência de Deus, conduziu John Arbuthnot e Johann Peter Süssmilch, entre outros, a recusar qualquer papel de relevo à contingência (os ratios encontrados não poderiam ser fruto do acaso) e à, consequente, interpretação da ordem subjacente aos nascimentos, mortes, casamentos..., em suma, das regularidades demográficas, como indícios de um determinado propósito e, em última análise, uma prova inabalável da ordem divina.

\section{BIBLIOGRAFIA}

Arendt, Hannah (1978). A Vida do Espírito: Querer (or. The Life of the Mind), Vol. II. Lisboa, Instituto Piaget (2000), 274 pp.

Arbuthnot, John (1710). An Argument for Divine Providence, Taken From The Constant Regularity Observed in the Births of Both Sexes. Philosophical Transactions of the Royal Society of London, 27, pág. 186-190.

In URL: http://www.taieb.net/fiches/arbuthnot.htm.

Arisawa, Hiromi (1957). La Loi des Grands Nombres et le Calcul des Probabilités dans la Première Édition de L'Ordre Divin. In SÜSSMILCH, Johann Peter (1979). L'ordre Divin aux Origines de la Démographie, Vol. I. Etudes Critiques, Biographie, Correspondance, Bibliographie. Trad. originale avec des études et commentaires rassemblés par Jacqueline Hecht. Paris, Institut

National d'Etudes Démographiques, pág. 23-31.

Bernstein, Peter L. (1996). Desafio aos Deuses. A Fascinante História do Risco (or. Against the Gods. The Remarkable Story of Risk). Rio de Janeiro, Editora Campus (1997), 389 pp.

Bonar, James (1931). Süssmilch, Derham et Malthus. In Süssmilch, Johann Peter (1979). L'ordre Divin aux Origines de la Démographie, Vol. I. Etudes Critiques, Biographie, 
Correspondance, Bibliographie. Trad. originale avec des études et commentaires rassemblés par Jacqueline Hecht. Paris, Institut National d'Etudes Démographiques, pág. 3-12.

Bricmont, Jean (2001). Science et Religion: L'irréductible Antagonisme.

In Dubessy, Jean; Lecointre, Guillaume (coor.) (2001). Intrusions

Spiritualistes et Impostures Intellectuelles en Sciences. Paris, Éditions Syllepse, pág. 121-138.

Daston, Lorraine (1988). Classical Probability in the Enlightenment. New Jersey, Princeton University Press (1995), 423 pp.

David, Florence Nightingale (1962). Games, Gods and Gambling. A History of Probability and Statistical Ideas. New York, Dover Publications (1998), 275 pp.

Diderot, Denis (1751). Arithmétique Politique. In Diderot, Denis; Alembert, D'. (Ed.) (1751). Encyclopédie ou Dictionnaire Raisonné des Sciences, des Arts et des Métiers, Vol. I. Paris, Briasson, David l'aîné , Le Breton, Durand, pág. 678-680.

Ferreira, Maria João; Tavares, Isabel; Turkman, Maria Antónia (2002).

Notas Sobre a História da Estatística. Dossiers Didácticos VI. In URL:

http://alea-estp.ine.pt/html/statofic/html/dossier/html/dossier.html

Foucault, Michel (1976). História da Sexualidade I. A Vontade de Saber (or. Histoire de la Sexualité 1. La Volonté de Savoir). Lisboa, Relógio D’Água (1994), 161 pp.

Foucault, Michel (1978). Segurança, Território e População (1977-1978). In Michel Foucault - Resumo dos Cursos do Collège de France (1970-1982). Rio de Janeiro, Jorge Zahar Editor (1997), pág. 79-86.

Gigerenzer, Gerd; Zeno Swijtink; Theodore Porter; Lorraine Daston; John Beatty; Lorenz Krüger (1989). The Empire of Chance: How Probability Changed Science and Everyday Life. Cambridge, Cambridge University Press (1997), 340 pp.

Graunt, John (1662). Natural and Political Observations Mentioned in a Following Index, and Made Upon the Bills of Mortality. London, John Martin, James Allestry, 74 pp. In URL:

http://www.ac.wwu.edu/ stephan/Graunt/bills.html

Hacking, Ian (1975). El Surgimento de la Probabilidad (or. The Emergence of Probability). Barcelona, Editorial Gedisa (1995), 258 pp.

Hacking, Ian (1990). La Domesticación del Azar. La Erosión del Determinismo y el Nacimiento de las Ciencias del Caos (or. The Taming of Chance). Barcelona, Gedisa (1991), 363 pp.

Hecht, Jacqueline (1979). La Vie et L'œuvre de Johann Peter Süssmilch. In Süssmilch, Johann Peter (1979). L'ordre Divin aux Origines de la Démographie, Vol. I. Etudes Critiques, Biographie, 
Correspondance, Bibliographie. Trad. originale avec des études et commentaires rassemblés par Jacqueline Hecht. Paris, Institut National d'Etudes Démographiques, pág. 65-161.

Howie, David (2002). Interpreting Probability. Controversies and Developments in the Early Twenty Century. Cambridge, Cambridge University Press, $262 \mathrm{pp}$.

Martins, Hermínio (2003). Aceleração, Progresso e Experimentum Humanum. In Garcia, José Luís; Martins, Hermínio (cord.) (2003). Dilemas da Civilização Tecnológica. Lisboa, ICS/UL, pág. 19-77.

Moxley, Roy A. (1999). The Two Skinners, Modern and Postmodern. In Behavior and Philosophy, Vol. 27, n. ${ }^{\circ}$ 2. Cambridge, Cambridge Center for Behavioral Studies, pág. 97-125.

Oberschall, Anthony (1987). The Two Empirical Roots of Social Theory and the Probability Revolution. In KRUGER, Lorenz; Gigerenzer, Gerd; Morgan, Mary S. (ed.) (1987). The Probabilistic Revolution. Vol. 2. Baskerville, Mit Press (1990), pág. 103-131.

Pasquino, Pasquale (1991). Theatrum Politicum: The Genealogy of Capital - Police and the State of Prosperity. In Graham Burchell, Colin Gordon \& Peter Miller (ed.) (1991). The Foucault Effect, Studies in Governmentality. Chicago: University of Chicago Press, pág. 105-118.

Süssmilch, Johann Peter (1741). Préface de Süssmilch à la Première Édition. In Süssmilch, Johann Peter (1765). L'ordre Divin aux Origines de la Démographie, Vol. II. L'oeuvre de J.P. Süssmilch : "L'ordre Divine". Trad. originale avec des études et commentaires rassemblés par Jacqueline Hecht. Paris, Institut National d'Etudes Démographiques (1979), pág. 291-295.

Süssmilch, Johann Peter (1765). L'ordre Divin aux Origines de la Démographie, Vol. II, L'oeuvre de J.P. Süssmilch : L'ordre Divin. Trad. originale avec des études et commentaires rassemblés par Jacqueline Hecht. Paris, Institut National d'Etudes Démographiques (1979), pág. 281-607.

Todhunter, Isaac. (1865). A History of the Mathematical Theory of Probability. From the Time of Pascal to that of Laplace. Cambridge, Macmillan and Co., 624 pp. 